\title{
Long-term omega-3 supplementation modulates behavior, hippocampal fatty acid concentration, neuronal progenitor proliferation and central TNF- $\alpha$ expression in 7 month old unchallenged mice
}

\author{
Trent Grundy ${ }^{1,2}$, Catherine Toben ${ }^{1}$, Emily J. Jaehne ${ }^{1}$, Frances Corrigan ${ }^{1}$ and Bernhard T. Baune ${ }^{\text {* }}$ \\ Discipline of Psychiatry, School of Medicine, University of Adelaide, Adelaide, SA, Australia \\ 2 School of Medicine and Dentistry, James Cook University, Townsville, OLD, Australia
}

Edited by:

Francesco Moccia, University of Pavia, Italy

\section{Reviewed by:}

Dmitry Lim, Università del Piemonte

Orientale "Amedeo Avogadro," Italy

Gursharan Chana, The University of

Melbourne, Australia

\section{*Correspondence:}

Bernhard T. Baune, Discipline of Psychiatry, School of Medicine, University of Adelaide, Level 4, Eleanor Harrald Building, Frome Road, Adelaide, SA 5005, Australia e-mail: bernhard.baune@ adelaide.edu.au
Dietary polyunsaturated fatty acid (PUFA) manipulation is being investigated as a potential therapeutic supplement to reduce the risk of developing age-related cognitive decline (ARCD). Animal studies suggest that high omega ( $\Omega$ )-3 and low $\Omega-6$ dietary content reduces cognitive decline by decreasing central nervous system (CNS) inflammation and modifying neuroimmune activity. However, no previous studies have investigated the long term effects of $\Omega-3$ and $\Omega-6$ dietary levels in healthy aging mice leaving the important question about the preventive effects of $\Omega-3$ and $\Omega-6$ on behavior and underlying molecular pathways unaddressed. We aimed to investigate the efficacy of long-term $\Omega-3$ and $\Omega-6$ PUFA dietary supplementation in mature adult C57BL/6 mice. We measured the effect of low, medium, and high $\Omega-3: \Omega-6$ dietary ratio, given from the age of 3-7 months, on anxiety and cognition-like behavior, hippocampal tissue expression of TNF- $\alpha$, markers of neuronal progenitor proliferation and gliogenesis and serum cytokine concentration. Our results show that a higher $\Omega-3: \Omega-6$ PUFA diet ratio increased hippocampal PUFA, increased anxiety, improved hippocampal dependent spatial memory and reduced hippocampal TNF- $\alpha$ levels compared to a low $\Omega-3: \Omega-6$ diet. Furthermore, serum TNF- $\alpha$ concentration was reduced in the higher $\Omega-3: \Omega-6$ PUFA ratio supplementation group while expression of the neuronal progenitor proliferation markers KI67 and doublecortin (DCX) was increased in the dentate gyrus as opposed to the low $\Omega-3: \Omega-6$ group. Conversely, $\Omega-3: \Omega-6$ dietary PUFA ratio had no significant effect on astrocyte or microglia number or cell death in the dentate gyrus. These results suggest that supplementation of PUFAs may delay aging effects on cognitive function in unchallenged mature adult C57BL/6 mice. This effect is possibly induced by increasing neuronal progenitor proliferation and reducing TNF- $\alpha$.

Keywords: polyunsaturated fatty acid, omega 3 , TNF- $\alpha$, neurogenesis, cognition

\section{INTRODUCTION}

The role of diet in the maintenance of mental health has long been recognized. Evidence suggests that the typical western diet is detrimental to the maintenance of cognitive function with aging (Francis and Stevenson, 2013). Recently, dietary interventions aimed at preventing cognitive decline have received attention, as it appears that diet across the entire lifespan plays a complex role in the development of cognitive decline (Gillette-Guyonnet et al., 2013). This suggests that early intervention, for example, up to middle age, may have more substantial benefits on cognitive function in later life as opposed to interventions in the elderly only.

Clinical trials have established that supplementation with omega $(\Omega)-3$, or a combination of $\Omega-3$ and $\Omega-6$ may have a role in the management and prevention of mild cognitive impairment (MCI) (Yehuda et al., 1996; Freund-Levi et al., 2006; Chiu et al., 2008; Yurko-Mauro et al., 2010). Animal studies demonstrate improved spatial recognition memory in aged mice after 7 weeks or 2 months of $\Omega-3$ polyunsaturated fatty acid (PUFA) supplementation (Jiang et al., 2009; Labrousse et al., 2012). Previous investigation into the mechanisms of this effect suggest that $\Omega-3$ PUFA supplementation has anti-inflammatory properties in aged mice (Labrousse et al., 2012) and increases neurogenesis in young mice (Kawakita et al., 2006), through stimulating brain derived neurotrophic factor (BDNF) and tropomyosin receptor kinase B (TrkB) expression (Jiang et al., 2009; Valente et al., 2009; Bhatia et al., 2011). Furthermore, it appears to reduce neuronal apoptosis after induced hypoxic injury (Zhang et al., 2010) through increasing anti-apoptotic proteins ( $\mathrm{Bcl}-\mathrm{xl}, \mathrm{Bcl}-2, \mathrm{Bfl}-1)$, while decreasing pro-apoptotic proteins (Bax, Bik) (Lukiw et al., 2005). It is also important to note that increased $\Omega-6$, or a low ratio of $\Omega 3: \Omega 6$, is also associated with impaired cognition and behavior in animal and human studies (Loef and Walach, 2013; Van Elst et al., 2014), although few studies have looked at this to date. 
Thus, far the effects of dietary intervention on cognition in mature mice up to 7 months of age, before the onset of any measurable impairment, have yet to be investigated. Furthermore, the majority of studies investigating $\Omega-3$ and $\Omega-6$ PUFA supplementation in animal models of cognitive dysfunction have used short term ( $\leq 2$ months) supplementation (Minogue et al., 2007; Petursdottir et al., 2008; Suchy et al., 2009; Labrousse et al., 2012), or $\Omega$-3 supplementation in animals previously deficient in $\Omega$ 3 (Hashimoto et al., 2002, 2005, 2009; McNamara et al., 2010). A recent systematic review suggested that long term $\Omega-3$ supplementation ( $>10 \%$ of animals lifespan) was most effective in reducing amyloid pathology and improving cognitive function (Hooijmans et al., 2012). Currently, studies that have examined a longer period of supplementation (3-12 months) have largely been limited to murine models of genetic predisposition to $\mathrm{AD}$ (Calon et al., 2004, 2005; Oksman et al., 2006; Arendash et al., 2007; Hooijmans et al., 2007; Arsenault et al., 2011). One such study in APPswe/PS1 $\triangle \mathrm{E} 9$ mice over 7 months found no significant protective effect (Arendash et al., 2007), while another study in 3xTG-AD mice identified that a high $\Omega-3$ diet improved exploration time (Arsenault et al., 2011). As diet is likely to affect predisposition to cognitive decline across the lifespan, the effects of modifying $\Omega-3-\Omega-6$ dietary intake supplementation until close to middle age ( 7 months of age) is important to consider.

Our study aimed to examine the preventative effect of longterm ( $~ 60 \%$ of lifetime) high $\Omega-3: \Omega-6$ dietary supplementation on predisposition to cognitive decline, and to examine the underlying mechanisms of this effect. While many people may only start to increase their intake of $\Omega-3$ dietary supplementation later in life, longer periods of supplementation may be more beneficial in the prevention of chronic disease such as cognitive decline (Simopoulos, 2011). This study utilized three different diets, a low $\Omega-3: \Omega-6$ ratio diet, a medium $\Omega-3: \Omega-6$ ratio diet and a high $\Omega$ 3: $\Omega-6$ ratio diet. Thus, the dose-related and $\Omega-3: \Omega-6$ ratio related effects of PUFA dietary modification on cognition-like behavior, neuroinflammation and neuronal progenitor proliferation in C57BL/6 mice were investigated.

\section{METHODS AND MATERIALS ANIMALS AND DIET}

Male $(n=18)$ and female $(n=12)$ C57BL/6NHsd mice, starting age 3 months, were used throughout the experiments. Ad libitum fed mice were housed in Laboratory Animal Services (LAS) Adelaide approved conditions with 3-5 animals per cage in individually ventilated cages (IVC) with a $12 \mathrm{~h}$ light/dark cycle. Handling and a general health examination including weighing of mice occurred twice per week. This study received ethics approval from the University of Adelaide animal ethics committee.

Mice were fed the AIN-93G mouse feed purchased from Specialty Feeds (Western Australia) from time of weaning until 3 months of age to ensure adequate growth and cognitive development. At 3 months of age, mice were randomly separated into three diet groups: low $\Omega-3: \Omega-6$, medium $\Omega-3: \Omega-6$, and high $\Omega$ 3: $\Omega-6$. The low $\Omega-3: \Omega-6$ diet incorporated $0.6 \mathrm{~g} / \mathrm{kg} \Omega-3$, with a 1:29 ratio of $\Omega-3: \Omega-6$, representing a similar $\Omega-3: \Omega-6$ ratio to current western diets (Blasbalg et al., 2011). The medium $\Omega-3: \Omega$ 6 diet incorporated $4.2 \mathrm{~g} / \mathrm{kg} \Omega-3$ with a $1: 3.6$ ratio of $\Omega-3: \Omega-6$, approximately similar to estimated human consumption in the year 1909 (1:6.7) (Blasbalg et al., 2011) and the estimated traditional evolutionary $\Omega-3: \Omega-6$ ratio (1:1) (Simopoulos, 2011), which is predicted to be more beneficial than the current intake levels (Simopoulos, 2011). The high $\Omega-3: \Omega-6$ diet incorporated $14.2 \mathrm{~g} / \mathrm{kg} \Omega-3$ with a $2: 1$ ratio of $\Omega-3: \Omega-6$, a level of supplementation beyond what could reasonably be achieved through modifying dietary intake to a more traditional composition (Simopoulos, 2011). For an overview of the fat content of each diet refer to Table 1. Modified diets were based on the AIN-93M adult mouse diet with $5 \%$ total fat and only differed in proportion of dietary fatty acids. The AIN-93G and AIN-93M mouse diets are formulations of feed designed for optimal animal health, with a known composition (Reeves et al., 1993). Diet was stored as dry pellets in a sealed vacuum container until required. Once opened, feed was stored at $4^{\circ} \mathrm{C}$. A full analysis of the composition of each diet is available in the supplementary information. The medium $\Omega 3: \Omega 6$ diet had fatty acid levels similar to those found in normal rodent chow used in the animal facility (Meat Free Rat and Mouse Diet (Speciality Feeds): total fat content $5 \%$, total $n-30.37 \%$, total $n-61.31 \%$, with a CV of $43 \%$ and $6 \%$ respectively). Mice were fed the modified diets for 4 months. A total of 30 mice [WT: low $\Omega-3: \Omega-6 n=10$ (7 male +3 female $)$, medium $\Omega-3: \Omega$ $6 n=10$ (6 male +4 female $)$, high $\Omega-3: \Omega-6 n=10$ (5 male + 5 female)], aged 7 months (middle age), were used for behavioral analyses. There were no differences in outcomes observed between male and female mice in any of the treatment groups. Due to the loose consistency of the feed pellets, many of which disintegrated and fell into the cage, we were unable to measure food intake.

\section{ASSESSMENT OF COGNITION-LIKE BEHAVIOR Open field}

The open field test was used to assess general locomotor activity and anxiety like behavior. It consists of a $40 \times 40 \mathrm{~cm}$ box with

Table 1 | Composition of fatty acids in experimental diets (\% weight of total fatty acids).

\begin{tabular}{lccc}
\hline Diets & Low $\mathbf{\Omega - 3} \mathbf{\Omega} \mathbf{- 6}$ & Med. $\boldsymbol{\Omega}-\mathbf{3 :} \mathbf{\Omega}-\mathbf{6}$ & High $\boldsymbol{\Omega}-\mathbf{3} \mathbf{\Omega} \mathbf{- 6}$ \\
\hline Total $\Omega-6$ & 1.76 & 1.52 & 0.70 \\
ARA & trace & 0.02 & 0.07 \\
LA & 1.75 & 1.48 & 0.56 \\
Total $\Omega-3$ & 0.06 & 0.42 & 1.42 \\
ALA & 0.04 & 0.03 & 0.02 \\
EPA & Trace & 0.06 & 0.23 \\
DHA & 0.04 & 0.28 & 1.03 \\
MUFA & 1.30 & 1.27 & 1.17 \\
PUFA & 1.82 & 1.95 & 2.14 \\
SFA & 1.69 & 1.59 & 1.40 \\
$\Omega$-3: $\Omega-6$ & $1: 29$ & $1: 3.6$ & $2: 1$
\end{tabular}

Composition of fatty acids in each diet, as a percentage of weight in the overall diet. $\Omega-3$ and $\Omega-6$ PUFA concentrations were achieved through altering quantities of clarified butter, maize oil and Numega Tuna oil. ARA, Arachidonic acid; LA, linolenic acid; ALA, alpha-Linolenic acid; EPA, Eicosapentaenoic acid; DHA, Docosahexaenoic acid; MUFA, monounsaturated fatty acid; PUFA, polyunsaturated fatty acid; SFA, saturated fatty acid. 
black walls $35 \mathrm{~cm}$ high into which each mouse was placed for 5 min while behavior was recorded according to published protocols (Baune et al., 2008; Gould et al., 2009; Hart et al., 2010). ANYMAZE recording software ( $\mathrm{v} 4.98$ ) was used to record total distance traveled and time spent in center.

\section{Barnes Maze}

The Barnes Maze was used to assess spatial learning and memory. It consists of an elevated circular table $(91 \mathrm{~cm}), 90 \mathrm{~cm}$ above the ground, with 20 circular holes evenly distributed around the periphery of the table. One hole lead to an escape box of sufficient size to house the mouse comfortably while the remaining 19 holes lead to false boxes of insufficient size to house the mouse. Bright overhead lighting provided incentive for the mouse to escape the exposed circular platform by locating the escape box. Barnes Maze procedures were carried out according to published protocols (McLay et al., 1998; Baune et al., 2008; McAfoose et al., 2009). Mice underwent 4 days of training during which each mouse was placed in the center of the apparatus under a cover which was removed at the beginning of the trial. If the escape hole was not located within $3 \mathrm{~min}$, the mouse was gently directed toward the escape hole, followed by relocation to the home cage. The apparatus was cleaned with $70 \%$ ethanol between each trial to eliminate olfactory cues. Each mouse received 3 trials per day separated by $15 \mathrm{~min}$. The average latency of the three trials was recorded. On day 5 two probe trials were given for $3 \mathrm{~min}$ each. The table was rotated so that the escape box was $90^{\circ}$ (probe trial 1) and $180^{\circ}$ (probe trial 2) from the original training position. Rotating the table and position of the hole should counteract any olfactory cues used to find the old location, as in a traditional probe trial with no hole. Time to find the old location of the escape box and time to find the new location were recorded. Latency to find the new location gives an indication that the mice learns the escape box has moved and tries to find it in a new position. Probe trial 2 should act as a type of extinction trial, where mice should no longer go straight to the old location (data is not shown). All movements, including latency to find the escape box were recorded using ANYMAZE software.

\section{MOLECULAR ANALYSES}

\section{Tissue processing}

Each mouse was injected with pentobarbitone $(60 \mathrm{mg} / \mathrm{kg})$. Adequate anesthesia was determined by the absence of limb and corneal reflexes. Blood was collected via cardiac puncture from half of the mice after which their brains were retrieved, fresh frozen in liquid nitrogen and stored at $-80^{\circ} \mathrm{C}$ for future protein analysis (WT: low $\Omega-3: \Omega-6 n=5$, medium $\Omega-3: \Omega-6 n=5$, high $\Omega-3: \Omega-6 n=5)$. The remaining halves of each treatment group were prepared for immunohistochemistry (IHC). These mice were perfused with a $10 \mathrm{ml}$ of $10 \%$ formalin solution through the left ventricle followed by retrieval of brain tissue and storage in $10 \%$ formalin (low $\Omega-3: \Omega-6 n=5$, medium $\Omega-3: \Omega-6 n=5$, high $\Omega-3: \Omega-6 n=5)$.

\section{Serum cytokine quantification}

Blood was centrifuged at $2500 \mathrm{rpm}$ for $10 \mathrm{~min}$, at least $30 \mathrm{~min}$ following collection, and serum was collected. Serum cytokine levels were measured using the BD Biosciences Cytometric Bead
Array (CBA) Mouse Inflammation Kit for the cytokines interleukin (IL)-6, IL-10, monocyte chemoattractant protein (MCP)1 , interferon (IFN) $-\gamma$, TNF- $\alpha$, and IL-12p70 according to the manufacturer's instructions. The theoretical lower detection per cytokine was; $5 \mathrm{pg} / \mathrm{ml}$ for IL-6, $17 \mathrm{pg} / \mathrm{ml}$ for IL-10, $52.7 \mathrm{pg} / \mathrm{ml}$ for MCP-1, $2.5 \mathrm{pg} / \mathrm{ml}$ for IFN- $\gamma, 7.3 \mathrm{pg} / \mathrm{ml}$ for TNF- $\alpha$ and $10.7 \mathrm{pg} / \mathrm{ml}$ for IL-12p70. The Aria (Beckman Coulter) was used to acquire 3000 events for each sample. Individual cytokine concentrations were identified by their fluorescent intensities (Fl-2) and were computed using the individual cytokine standard reference curve using the FCAP Array v3 software (BD Biosciences).

\section{Immunohistochemistry}

Brains were embedded in paraffin prior to sectioning, with a series of nine $5 \mu \mathrm{m}$ sections collected at $200 \mu \mathrm{m}$ intervals from Bregma -1.3 to -3.1 , allowing a comprehensive analysis of the hippocampus. Immunohistochemistry was then performed to examine levels of TNF- $\alpha$ (R\&D: AF410-NA), doublecortin (DCX) (Millipore: AB2293), Ki67 (Abcam: AB15580), GFAP (Novocastra: NCL:GFAP:GA5), IBA-1 (Santa-Cruz: 28528), caspase-3 (Biovision: 3138-100), and oxo8dG/oxo8G (QED Bioscience 12501). Following de-waxing and dehydration, endogenous peroxidase activity was blocked by incubation with $0.5 \%$ hydrogen peroxide in methanol for $30 \mathrm{~min}$. Slides were then washed $2 \times 3 \mathrm{~min}$ in phosphate buffered saline (PBS) before antigen retrieval by heating at close to boiling point for $10 \mathrm{~min}$ (TRIS for doublecortin, citrate for others). Once the slides had cooled below $40^{\circ} \mathrm{C}$ they were washed with PBS before being blocked with $3 \%$ normal horse serum in PBS for $30 \mathrm{~min}$. The appropriate primary antibody was applied to the slides which were left to incubate at room temperature overnight (TNF- $\alpha$ 1:300, IBA1 1:1000, caspase-3 1:1000, Ki67 1:2000, doublecortin 1:8000, GFAP 1:40000, oxo8dG/oxo8G 1:8000).

The next day slides were washed in $2 \times 3$ min of PBS before the appropriate species of IgG biotintylated antibody was added for $30 \mathrm{~min}$ (Dako). After another PBS wash, slides were incubated with streptavidin peroxidase conjugate for $60 \mathrm{~min}$ followed by another rinse with PBS. The immunocomplex was then visualized with precipitation of DAB (Sigma D-5637) in the presence of hydrogen peroxide. Slides were washed to remove excess DAB and lightly counterstained with haematoxylin, dehydrated and mounted with DePeX from histolene.

Slides were subsequently digitally scanned using the Hamamatsu NanoZoomer and examined using the associated NDP.view2 software (Hamamatsu). Sequential images were captured of the hippocampus consisting of the cornu ammonis, dentate gyrus and hippocampal formation and exported for manual cell counting using the inbuilt software within Image J $1.46(\mathrm{NIH})$. The number of positive cells were then counted at $40 \times$ magnification within each hippocampus (or dentate gyrus alone depending on the immunohistochemical stain) of each slide. For the stains TNF- $\alpha$, anti-caspase 3, Ki67, and DCX, all positive cells in the relevant brain areas were counted and recorded through the use of the cell tracking tool provided with the software. For GFAP and IBA-1, the image was overlaid with $120 \times 120 \mu \mathrm{m}$ grids, and every second grid for IBA- 1 or 10 consistent representative grids for GFAP were counted with the total being corrected for the total area to determine the number 
of immunopositive cells. The size of the hippocampus or dentate gyrus was then measured within the NDP view software to allowing the final measurement to be expressed as cells $/ \mathrm{mm}^{2}$. For oxidative stress, the dentate gyrus region from each mouse was ranked on a scale from 0 to 3 , with $0=$ no staining, $1=$ light staining, $2=$ moderate staining and $3=$ strong staining. The researcher was blinded to the study group of the slides during the slide analysis process. The Coefficient of error was calculated by comparing the total number of immunopositive cells for each subject within each diet and stain to identify the mean and standard error of the mean. The Coefficient of error then was the result of the SEM divided by the Mean. For hippocampal TNF $\alpha$, the CE for the for high $\Omega-3: \Omega-6$ mice was 0.06 , for medium $\Omega-3: \Omega-6$ mice was 0.12 and for low $\Omega-3: \Omega-6$ was 0.10 . For TNF- $\alpha$ in the dentate gyrus, the CE was $0.29,0.21$, and 0.31 for high, medium and low $\Omega-3: \Omega-6$ mice, respectively. For DCX the CE values were $0.17,0.18$, and 0.05 for high, medium and low $\Omega-3: \Omega-6$ mice, respectively. For Ki67 the CE values were 0.17, 0.17 , and 0.19 for high, medium and low $\Omega-3-\Omega-6$ mice. For GFAP the CE values were $0.04,0.12$, and 0.04 for high medium and low $\Omega-3: \Omega-6$ mice. For IBA-1, CE values were $0.07,0.06$, and 0.08 for high, medium and low $\Omega-3: \Omega-6$ mice and for caspase-3 CE values were $0.20,0.17$, and 0.17 for high, medium and low $\Omega-3: \Omega-6$ mice, respectively.

\section{Free fatty acid analyses}

Analyses of free fatty acids were carried out by the Waite Analytical Services. Briefly the standardized protocol extracted total lipids from thawed hippocampi tissue samples utilizing a modified Bligh and Dyer method with the addition of heptadecanoic acid as an internal standard (Tu et al., 2013). Free fatty acids were separated via thin layer chromatography and methylated and then analyzed via gas chromatography. The resultant fatty acid methyl esters were identified based on the retention time of standards obtained by Nucheck Prep Inc. (Elysian MN) using the Hewlett-Packard Chemstation data system. Free fatty acids were quantified as a percentage of hippocampal tissue sample.

\section{STATISTICAL ANALYSES}

All data was analyzed using Graphpad PRISM software (version 6.02). Data was tested for Gaussian distribution using the D'Agostino-Pearson omnibus test. All data passed Normality testing. For Barnes maze learning analysis repeated measures Two-Way ANOVA with Tukey's multiple comparisons test was used, to show whether groups showed significant learning or not. For all other data, comparisons of the effect of different diets within mouse strains were tested using One-Way ANOVA with Tukey's post-hoc test comparisons. For all results, a $p$-value of $<0.05$ was considered significant. All data is represented as mean values $\pm \mathrm{SEM}$.

\section{RESULTS}

THE EFFECT OF $\Omega-3: \Omega-6$ SUPPLEMENTATION ON WEIGHT AND GENERAL OPEN FIELD MEASURES

Mice were weighed immediately prior to euthanasia. Mice in the low $\Omega-3: \Omega-6$ group $(28.5 \pm 0.95 \mathrm{~g})$ were found to be significantly lighter than medium $\Omega-3: \Omega-6(35.7 \pm 1.78 \mathrm{~g})$ and high $\Omega-3: \Omega$ 6 diet $(34.4 \pm 1.73 \mathrm{~g}$ ) mice (One-Way ANOVA $F=6.28, p=$ 0.006 , Tukey's post-hoc test $p=0.007, p=0.029$, respectively). There was however no significant correlation between weight and anxiety or weight and immunohistochemistry stain count when analyzed using Pearson correlation.

Differences in locomotor activity were investigated by recording the distance traveled during the Open Field test. No locomotor differences were observed between low, medium or high $\Omega-3: \Omega-6$ diet groups (One-Way ANOVA $F=0.14, p=0.87$ ) (Figure 1A).

Anxiety-like behavior was measured in the open field test whereby time spent in the center of the field represents reduced anxiety-like behavior (Flint, 2003; Hart et al., 2010). One-Way ANOVA $(F=3.97, p=0.032)$ with Tukey's post-hoc test showed that mice in the high $\Omega-3: \Omega-6$ diet group spent significantly less time in the center of the open field compared to the low $\Omega-3: \Omega$ 6 group $(p=0.047)$, with a trend to also spend less time than the medium $\Omega-3: \Omega-6$ group ( $p=0.068$ ). These results show that the high $\Omega-3: \Omega-6$ diet leads to increased anxiety in the open field (Figure 1B).

\section{INVESTIGATING EFFECTS OF $\Omega$-3: $\Omega 6$ DIETARY SUPPLEMENTATION ON SPATIAL LEARNING}

The Barnes Maze was used to investigate learning behavior as described. Learning ability was inferred from reduced latency to locate the escape hole on subsequent training days over 4 days. A repeated measures Two-Way ANOVA was used to analyses latency by Diet and by Day, showing a significant effect of day of training $(F=13.0, p<0.0001)$ but not of $\operatorname{diet}(F=0.55, p=0.59)$ or interaction $(F=0.85, p=0.54)$ (Figure 2$)$. Tukey's post-hoc comparison of day effect suggests that both the medium and high $\Omega-3: \Omega-6$ diet groups showed significant learning over the 4 days, with latency on Day 1 significantly higher than on Day 4 in both the medium $(p=0.0047)$ and high $\Omega-3: \Omega-6$ diet groups $(p=$ $0.0004)$. There were no significant differences between latency on any days for mice in the low $\Omega-3: \Omega-6$ diet group. These observations suggest that the intake of a high or medium concentration of dietary $\Omega$-3 PUFA's improve the ability of mice to learn across 4 days.

Table 2 shows results of the Probe trial 1, where the escape box was rotated $90^{\circ}$ from the old location. One-Way ANOVA showed no difference between diet groups in latency to find the old location ( $p=0.67, F=0.40)$ indicating similar spatial memory across all strains, or in time taken to enter the new location $(p=0.94, F=0.06)$.

\section{EXAMINING EFFECTS OF $\Omega-3: \Omega-6$ SUPPLEMENTATION ON SERUM CYTOKINE EXPRESSION}

One-Way ANOVA showed a difference between diet groups in both IFN- $\gamma(F=10.3, p=0.0047)$ and TNF- $\alpha(F=6.81, p=$ $0.01)$. Tukey's post-hoc analysis indicated that both cytokines were increased in the low $\Omega-3: \Omega-6$ diet group compared to the medium (IFN- $\gamma p=0.0068$, TNF- $\alpha p=0.029)$ and high $($ IFN- $\gamma$ $p=0.0078$, TNF- $\alpha p=0.014$ ) diet groups (Table 3). No differences between diet groups were observed for the remaining inflammatory markers (IL-6, IL-10, MCP-1, or IL-12; One-Way ANOVA, all $p>0.05$ ). 


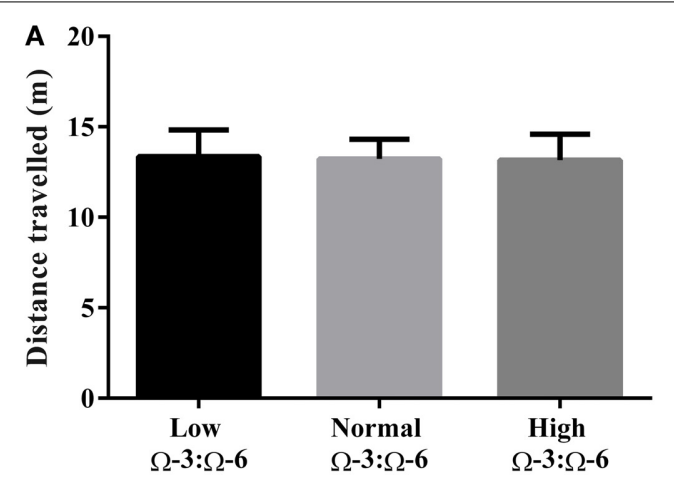

FIGURE 1 | Locomotor activity and anxiety in the open field. (A) Locomotor activity of mice in the open field measured by distance traveled and $\mathbf{B}$ ) anxiety-like behavior in mice measured by time spent in the center of

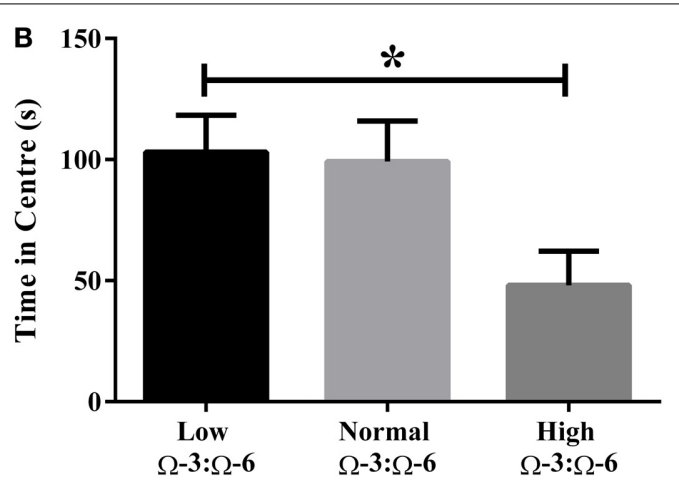

the open field. Data analyzed by One-Way ANOVA within strains with Tukey's post-hoc test, ${ }^{*} p<0.05$, as indicated on figure. All data presented as mean $\pm \operatorname{SEM}(n=10 /$ group).

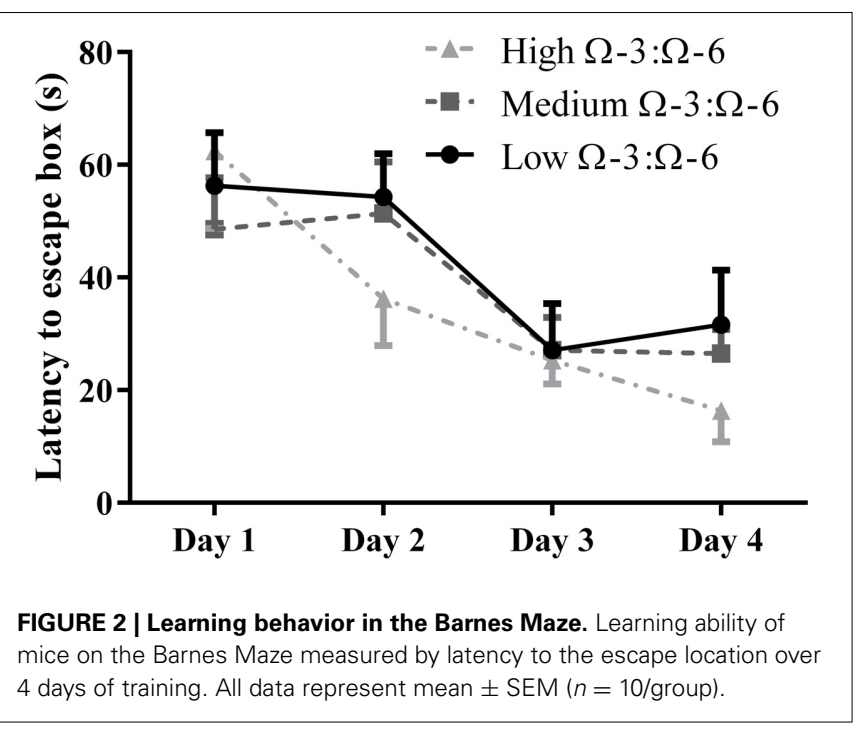

Table 2 | Probe Trial measures of Barnes Maze (retention memory).

\begin{tabular}{lcc}
\hline & $\begin{array}{c}\text { Time to Find old } \\
\text { escape box location (s) }\end{array}$ & $\begin{array}{c}\text { Time to enter new } \\
\text { escape box location (s) }\end{array}$ \\
\hline Low $\Omega-3: \Omega-6$ & $72.3 \pm 22.3$ & $136.8 \pm 14.3$ \\
Medium $\Omega-3: \Omega-6$ & $89.0 \pm 24.6$ & $138.8 \pm 19.9$ \\
High $\Omega-3: \Omega-6$ & $60.3 \pm 17.6$ & $130.1 \pm 19.3$ \\
\hline
\end{tabular}

Barnes Maze probe trial measures. Data analyzed by One-Way ANOVA. Data represents mean $\pm S E M(n=10 /$ group $)$.

\section{EFFECTS OF $\Omega-3: \Omega-6$ SUPPLEMENTATION ON EXPRESSION OF THE PRO-INFLAMMATORY CYTOKINE TNF- $\alpha$ IN THE HIPPOCAMPUS}

The hippocampus (including the cornu ammonis, dentate gyrus and hippocampal formation) was investigated due to its' role in spatial learning and memory (Jarrard, 1993; Rolls and Kesner, 2006; Neves et al., 2008). Within the hippocampus, the dentate gyrus was also investigated due to its role in memory and in neurogenesis (Neves et al., 2008). The cytokine TNF- $\alpha$ was investigated due to its' critical role in learning and memory. Recent evidence suggests that a basal level of TNF- $\alpha$ is required for normal memory and learning however excessive levels may be detrimental (Baune et al., 2008; McAfoose and Baune, 2009; Camara et al., 2013). Hippocampal TNF- $\alpha$ positive cells were reduced in a dose dependent manner as shown by less TNF- $\alpha$ positive cells with increasing $\Omega-3$ dietary concentration (OneWay ANOVA $F=16.55, p<0.001$; Tukeys' post-hoc test low $\Omega-3: \Omega-6$ vs. medium $\Omega-3: \Omega-6 p=0.025$, low $\Omega-3: \Omega-6$ vs. high $\Omega-3: \Omega-6 p=0.0003$, medium $\Omega-3: \Omega-6$ vs. high $\Omega-3: \Omega-6 p=$ 0.041) (Figure 3A). Furthermore, when the dentate gyrus was examined separately, the high $\Omega-3: \Omega-6$ diet mice had significantly less TNF- $\alpha$ expression than low $\Omega-3: \Omega-6$ diet mice (One-Way ANOVA $F=4.45, p=0.038$; Tukeys' post-hoc test $p=0.036$ ) (Figure 3B). A representative image of TNF- $\alpha$ expression in the dentate gyrus is depicted in Figure 4. These results suggest that higher $\Omega-3: \Omega-6$ dietary ratio's reduced the expression of the pro-inflammatory cytokine TNF- $\alpha$ in the hippocampus and the dentate gyrus.

\section{EFFECTS OF $\Omega-3: \Omega-6$ SUPPLEMENTATION ON NEURONAL PROGENITOR} PROLIFERATION AND GLIOGENESIS MARKERS IN THE DENTATE GYRUS To investigate the effect of $\Omega-3$ on neuronal progenitor proliferation, KI67 (proliferating cells) and DCX (immature neurons) expression in the dentate gyrus were examined by staining hippocampal slices with anti-Ki67 antibodies and anti-DCX antibodies. Gliogenesis in the hippocampus was investigated by staining of hippocampal slices with anti-GFAP (astrocyte marker) and anti-IBA-1 (microglia marker) antibodies. The subsequent slides were digitally imaged followed by manual examination.

Under physiological conditions, the high $\Omega-3: \Omega-6$ diet group showed a significant increase in Ki67 and DCX positive cells in the dentate gyrus compared to the low and medium $\Omega$ 3: $\Omega-6$ diet groups (Ki67: One-Way ANOVA $F=5.21 p=0.026$; Tukeys' post-hoc test $p=0.030, p=0.048$, respectively; DCX One-Way ANOVA $F=6.70, p=0.011$; Tukeys' post-hoc test $p=0.0 .035, p=0.013$, respectively) (Figures 5A,B). The representative images of these stains can be viewed in Figures 6, 7. In contrast, dietary $\Omega-3: \Omega-6$ ratio content was found not to modify microglia or astrocyte number in the hippocampus 
Table 3 | Serum cytokine levels.

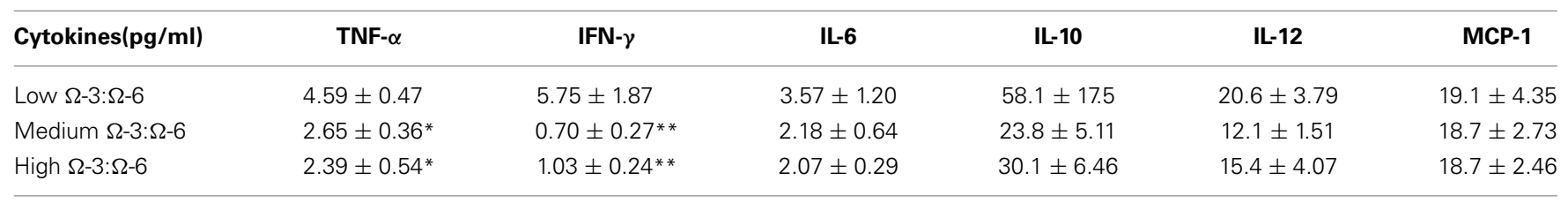

Representation of cytokines in serum measured by CBA. Data analyzed by One-Way ANOVA with Tukey's post-hoc test. ${ }^{*} p<0.05,{ }^{* *} p<0.01$ C.F. low $\Omega-3$ diet. Data represents mean \pm SEM ( $n=5 /$ group).

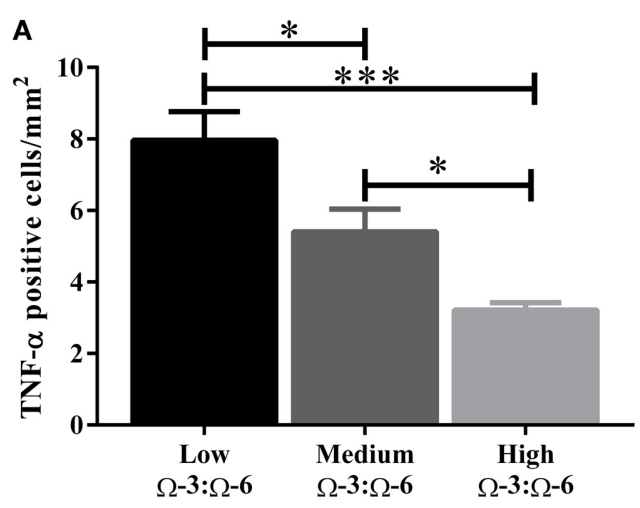

FIGURE 3 | Total number of TNF- $\alpha$ positive cells in the hippocampus. The total number of TNF- $\alpha$ positive cells in (A) the hippocampus (including the dentate gyrus) and (B) the dentate gyrus only. Data analyzed by

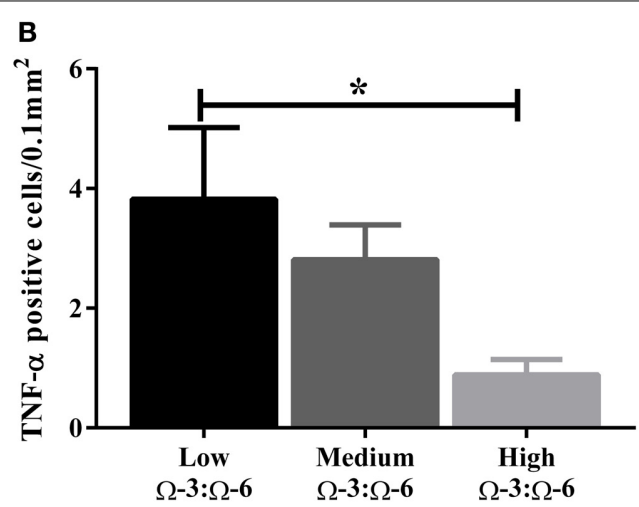

One-Way ANOVA within strains with Tukey's post-hoc test, ${ }^{*} p<0.05$, ${ }^{* * *} p<0.001$, as indicated on figure. All data presented as mean $\pm \mathrm{SEM}$ ( $n=5 /$ group).
[One-Way ANOVA microglia (IBA-1) $F=2.40, p=0.13$, astrocytes (GFAP) $F=0.20, p=0.82$ ] (representative images can be seen in Supplementary Figures 1,2). This indicates that the increase in cell proliferation in high $\Omega-3: \Omega-6$ mice was not associated with an increase in astrocyte or microglial number.

\section{EFFECTS OF $\Omega-3: \Omega-6$ SUPPLEMENTATION ON OXIDATIVE STRESS AND CELL DEATH IN THE DENTATE GYRUS}

Oxidative stress was investigated through staining hippocampal slices with an antibody to oxo8dG/oxo8G which measures DNA/RNA oxidative damage. Dietary $\Omega-3: \Omega-6$ ratio modified the level of oxidative stress, with a significant difference between the median of each group (Kruskal Wallis $p<0.05$ ), with the low $\Omega$ $3: \Omega-6$ diet having a median of 2 , representing moderate levels of staining compared to a median of 1 , indicating a low level of staining in the medium and high $\Omega-3: \Omega-6$ diet groups (Figure 8).

Similarly, cell death was investigated through staining hippocampal slices with anti-caspase 3 antibodies (a protein involved in cell apoptosis) and examination of digital images. The dentate gyrus was investigated to determine if the increase in cell proliferation and immature neurons was associated with an increase in cell death. Dietary $\Omega-3: \Omega-6$ ratio was not found to modify cell death in the dentate gyrus (One-Way ANOVA $F=0.54$, $p=0.59$ ) (representative images can be viewed in Supplementary Figure 3).

\section{FREE FATTY ACID ANALYSIS OF THE HIPPOCAMPUS}

Analysis of $\Omega-3$ and $\Omega-6$ concentrations in the hippocampus of test mice confirmed that alterations in dietary levels of PUFAs do translate to the brain and that mice did consume enough of the pellets to see a change (Table 4). Concentration of $\Omega-3$ increased from the low to high $\Omega-3: \Omega-6$ groups (One-Way ANOVA $p=$ $0.0031)$ and Tukey's post-hoc test showed that the low $\Omega-3: \Omega-6$ group had significantly lower levels of $\Omega-3$ in the hippocampus than both the medium $(p=0.037)$ and high $\Omega-3: \Omega-6$ groups $(p=0.0027)$. Concentration of $\Omega-6$ also decreased from the low to high $\Omega-3: \Omega-6$ groups (One-Way ANOVA $p=0.0003$ ) and Tukey's post-hoc test showed that the high $\Omega-3: \Omega-6$ group had significantly lower levels of $\Omega-6$ in the hippocampus than both the medium $(p=0.0022)$ and low $\Omega-3: \Omega-6$ groups $(p=0.0004)$. Analysis of $\Omega-3: \Omega-6$ ratio in the hippocampus also confirmed the expected differences based on diet. One-Way ANOVA $(p<$ $0.0001)$ showed that the low $\Omega-3: \Omega-6$ group had a significantly lower ratio than both the medium $(p=0.026)$ and high $\Omega-3: \Omega-6$ diets groups $(p<0.0001)$ while the medium $\Omega-3: \Omega-6$ diet group also showed a significantly lower ratio than the high $\Omega-3: \Omega-6$ diet group $(p=0.0022)$.

\section{DISCUSSION}

This study demonstrated that long-term supplementation and increasing the dietary ratio of $\Omega-3: \Omega-6$ PUFA in unchallenged mature adult ( 7 month old) WT mice leads to increased anxiety and improved hippocampal dependent spatial memory, with increases in neuronal progenitor proliferation and decreases in TNF- $\alpha$ expression, as well as oxidative stress, within the hippocampus. The effects on behavior, TNF- $\alpha$ expression and neuronal progenitor proliferation appeared to be dose dependent, with the high $\Omega-3: \Omega-6$ diet group demonstrating the highest 


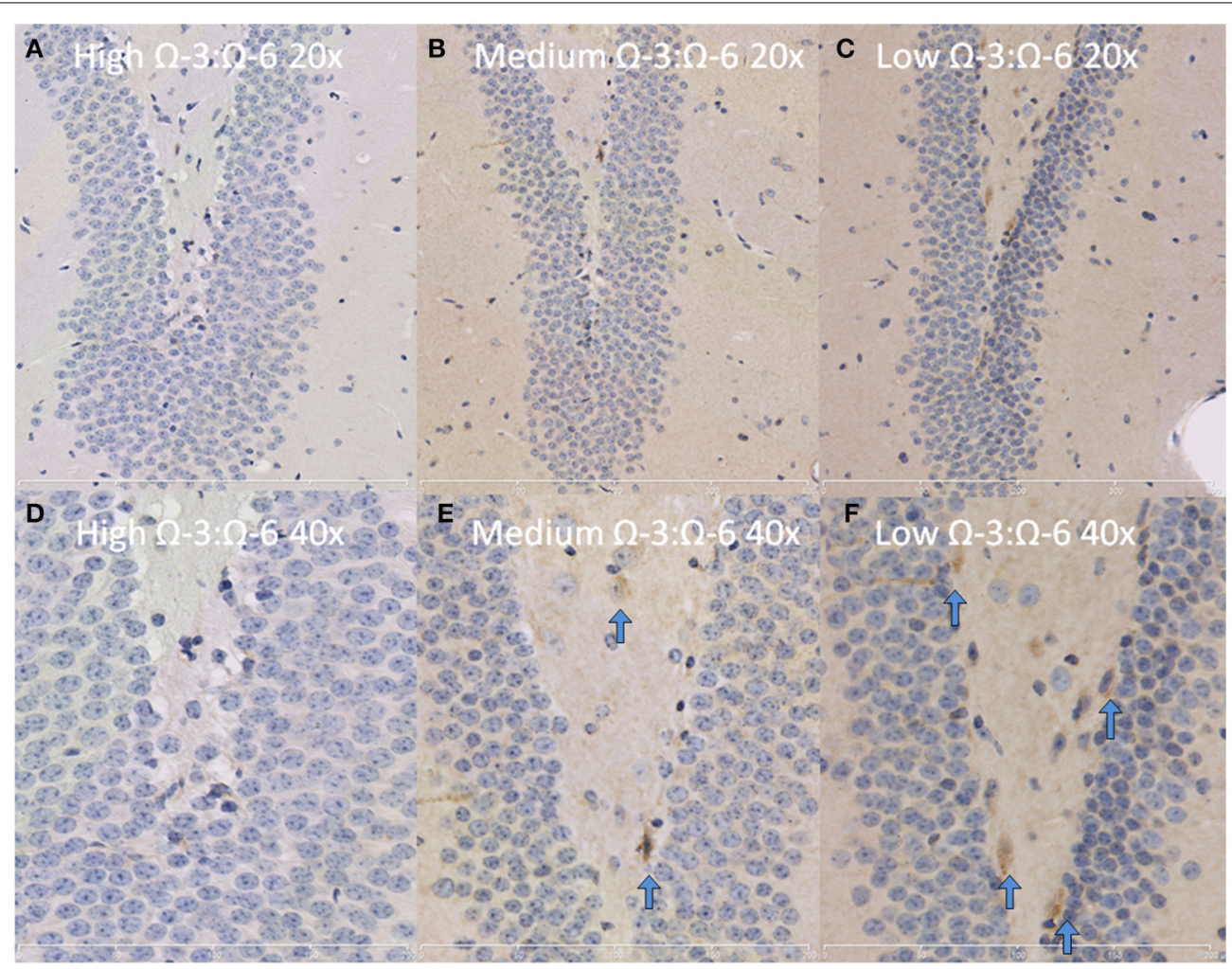

FIGURE 4 | Representative images of TNF- $\alpha$ expression in the dentate gyrus. Representative images of the hippocampus centered on the dentate gyrus to demonstrate expression of TNF- $\alpha$ positive cells at $20 \times$ magnification in (A) High $\Omega-3: \Omega-6$ mice, (B) medium $\Omega-3: \Omega-6$ mice, (C) low $\Omega-3: \Omega-6$ mice and at $40 \times$ magnification in (D-F), respectively. Arrows signify relevant stained cells.

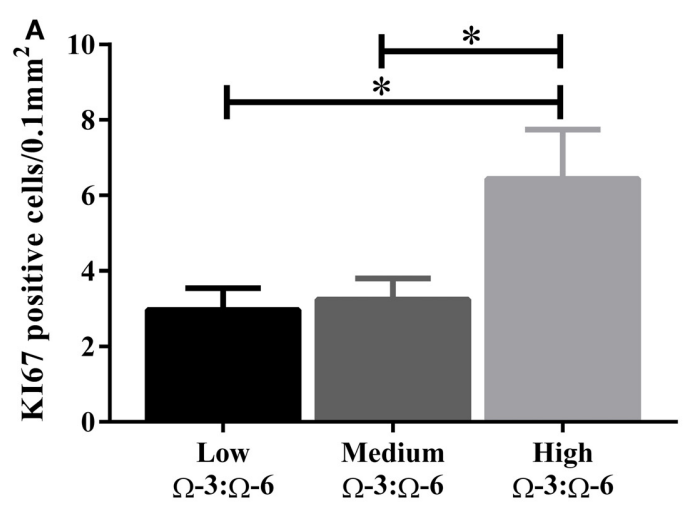

FIGURE 5 | Effect of $\Omega-3: \Omega-6$ diet on neurogenesis in the dentate gyrus. Number of KI67 positive cells (A) and DCX positive cells (B) in the dentate gyrus. Data analyzed by

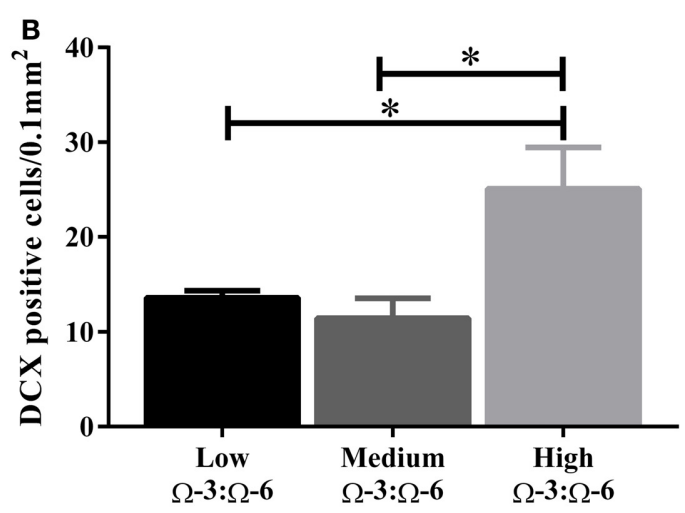

One-Way ANOVA within strains with Tukey's post-hoc test, ${ }^{*} p<0.05$ as indicated on figure. All data represented as mean \pm SEM ( $n=5 /$ group). levels of anxiety and significant learning in the Barnes Maze, the lowest number of TNF- $\alpha$ positive cells within the hippocampus, and the highest rate of neurogenesis whilst the low $\Omega-3: \Omega-6$ diet group had the worst performance on the Barnes Maze, the highest TNF- $\alpha$ expression and the highest levels of oxidative stress. This suggests that $\Omega-3$ diet and $\Omega-3: \Omega-6$ ratios may play an important role in maintaining normal behavior throughout life.
The three different doses of $\Omega-3$ supplementation used in this study were designed to represent relevant human equivalent quantities of $\Omega-3$ and $\Omega-6$ consumption. The low $\Omega-3: \Omega-6$ diet corresponds to a typical western diet, the medium $\Omega-3: \Omega-6$ diet represents a physiologically traditional diet, while the high $\Omega-3: \Omega-6$ diet represents considerably higher supplementation again (Blasbalg et al., 2011; Simopoulos, 2011). As previously discussed, increasing dietary $\Omega-3$ increases the $\Omega-3: \Omega-6$ ratio, 


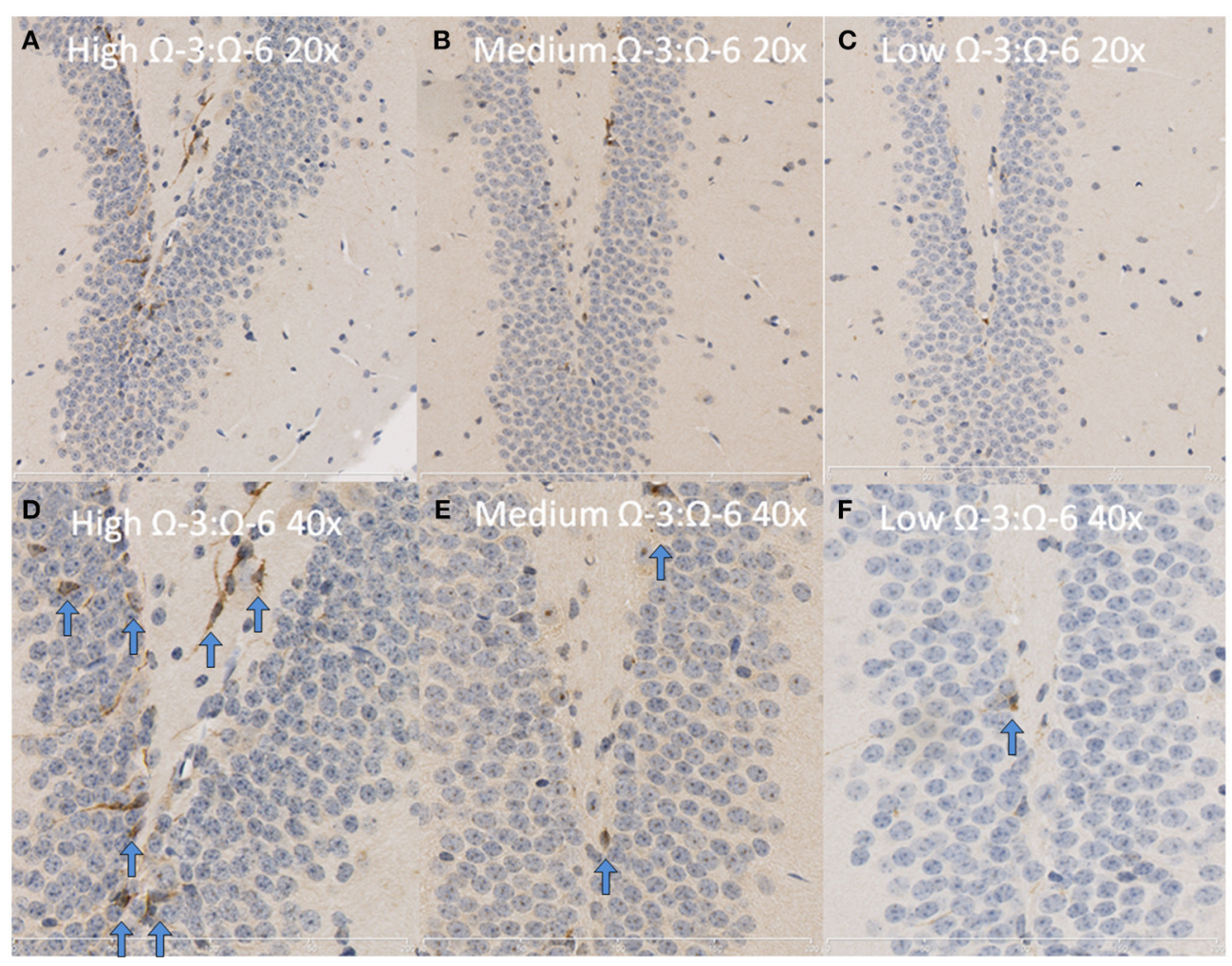

FIGURE 6 |Representative images of DCX expression in the dentate gyrus. Representative images of the hippocampus centered on the dentate gyrus to demonstrate expression of DCX positive cells at $20 \times$ magnification in (A) high $\Omega-3: \Omega-6$ mice, (B) medium $\Omega-3: \Omega-6$ mice, (C) low $\Omega-3: \Omega-6$ mice and at $40 \times$ magnification in (D-F), respectively. Arrows signify relevant stained cells. allowing for higher concentrations of $\Omega-3$ derived metabolites to form, which are considerably less pro-inflammatory than their $\Omega-6$ derived counterparts (Wall et al., 2010). The use of specially designed lab diets based on the AIN-93 M standard was done to eliminate the inherent variability in standard lab chow diets. It should be noted that for the first 2 months after weaning, mice were fed with a standard diet (AIN- 93G) designed to support a healthy development. Any effect of dietary $\Omega-3: \Omega-6$ supplementation thereafter can be attributed to the effect of $\Omega$ 3 supplementation and $\Omega-6$ reduction on adult central nervous system function, and not due to $\Omega-3$ deficiency during neurodevelopment, which has been previously documented (Gibson et al., 2001; Salem et al., 2001; Ryan et al., 2010; Bhatia et al., 2011; Rombaldi Bernardi et al., 2012). Furthermore, our modified diets were given for 4 months ( $~ 60 \%$ of lifespan), where supplementation $>10 \%$ of lifespan has previously been suggested to be beneficial (Hooijmans et al., 2012). Previous shorter-term studies have demonstrated that 8 weeks of high $\Omega-3$ diet supplementation attenuated age related increases in TNF- $\alpha$, IL- 6 and IL- $1 \beta$ and improved spatial memory as compared to an $\Omega-3$ deficient diet (Labrousse et al., 2012). No previous studies using a treatment as long as this one in unchallenged aged mice have been performed. The longer-term supplementation given in this study directs focus on the preventative actions of a high $\Omega-3-\Omega-6$ PUFA diet ratio in healthy, unchallenged mice up to middle age during early adulthood. Our results represent evidence for a preventative action of a high $\Omega-3: \Omega-6$ ratio against cognitive decline associated with early aging. It is important to note that higher dietary $\Omega-3: \Omega-6$ dietary concentrations resulted in increased hippocampal $\Omega-3: \Omega-6$ concentrations. This confirms that mice consumed as adequate amount of each diet, and that dietary PUFA modulated brain PUFA concentration thus providing an explanation for the central effects of ingested fatty acids. We did note that the mice consuming the medium and high $\Omega-3: \Omega-6$ PUFA diet were significantly heavier than the mice consuming the low $\Omega-3: \Omega-6$ diet. Previous reviews have linked obesity to higher levels of proinflammatory cytokines (Lumeng and Saltiel, 2011), and thus, as the higher $\Omega-3: \Omega-6$ PUFA diets resulted in reduced inflammation, the weight of mice is unlikely to have played a role.

No differences in locomotor activity were seen in the open field following different diets, however the high $\Omega-3: \Omega-6$ PUFA diet led to lower time spent in the center of the open field, suggesting increased anxiety. Previous studies investigating similar parameters have shown varying results following $\Omega-3$ deficiency or supplementation (Fedorova and Salem, 2006). For example, several studies showed no difference between $\Omega$-3 deficient and control mice (Nakashima et al., 1993; Carrié et al., 2000a), or between high, low and normal $\Omega-3$ : $\Omega-6$ diet groups, consistent with our study (Wainwright et al., 1997). However, other studies have shown $\Omega$-3 deficient mice to have increased locomotor activity (Umezawa et al., 1995; Raygada et al., 1998; Fedorova and Salem, 2006) or mice given high $\Omega$-3 diets had reduced activity 


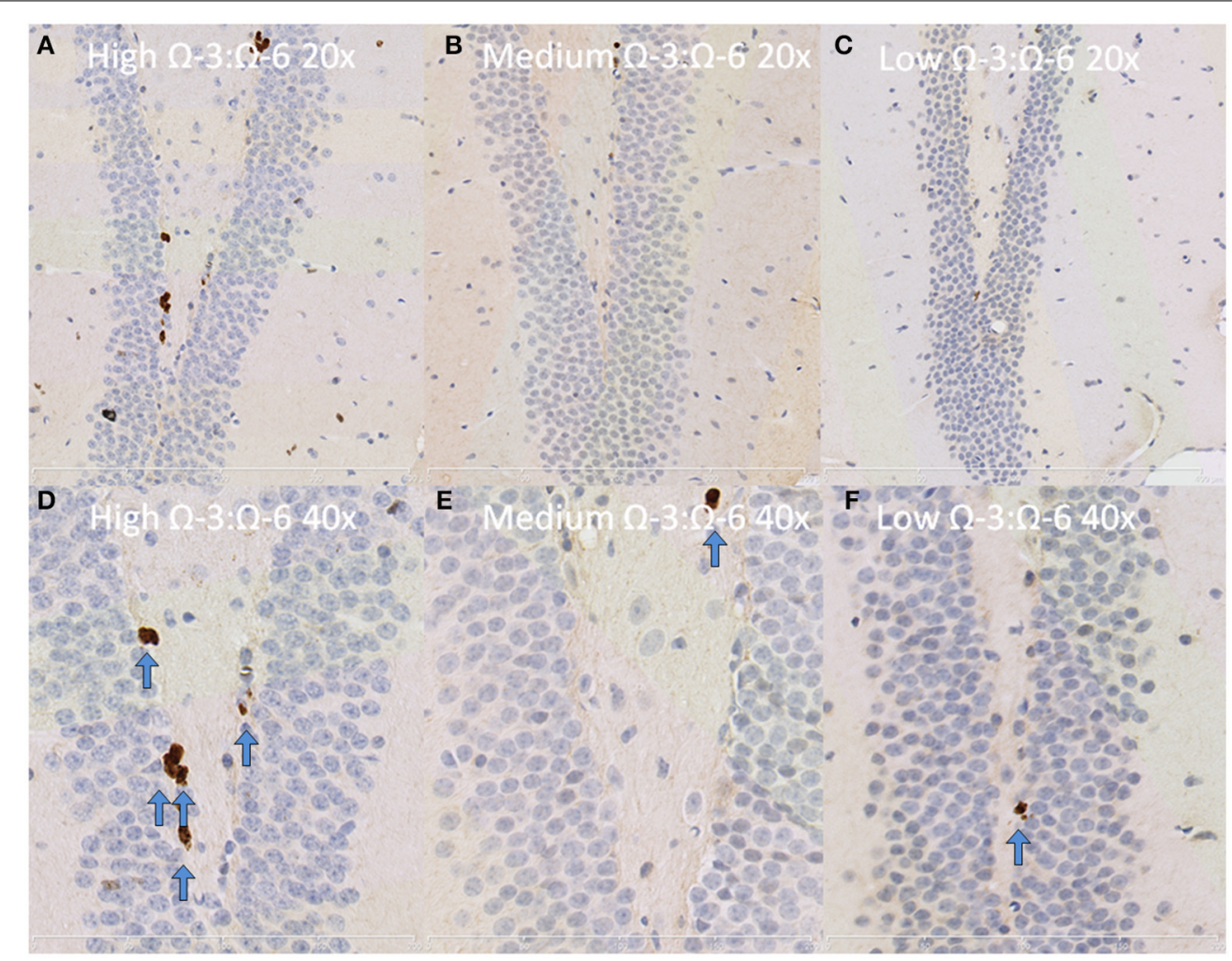

FIGURE 7 | Representative images of Ki67 expression in the dentate gyrus. Representative images of the hippocampus centered on the dentate gyrus to demonstrate expression of Ki67 positive cells at $20 \times$ magnification in (A) high $\Omega-3: \Omega-6$ mice, (B) medium $\Omega-3: \Omega-6$ mice, (C) low $\Omega-3: \Omega-6$ mice and at $40 \times$ magnification in (D-F), respectively. Arrows signify relevant stained cells.
(Rockett et al., 2012), while further studies have shown different effects of diet depending on age (Carrié et al., 2000b). All of these studies have used different methods to measure locomotor activity, as well as different dosing protocols, including the use of different foods to increase or decrease $\Omega-3$ consumption and either giving it directly to the study mice at different ages or giving it to the mother before and during gestation, therefore direct comparison between studies is difficult. Similarly, various studies have shown different effects on anxiety behavior in animals after altering $\Omega-3: \Omega-6$ PUFA levels in their diet (Fedorova and Salem, 2006). $\Omega-3$ deficient mice have previously been shown to have everything from decreased anxiety (Nakashima et al., 1993; Francès et al., 1995), increased anxiety (Carrié et al., 2000a; Fedorova and Salem, 2006), or no change in anxiety measured by time spent in the open arm of an elevated plus maze (Belzung et al., 1998; Moriguchi et al., 2000).

Despite the high $\Omega-3: \Omega-6$ PUFA diet leading to increased anxiety in the open field, as it has been suggested that anxiety may exacerbate poor memory (Spencer et al., 2010), the $\Omega-3: \Omega-6$ PUFA ratio within the diet appears to be important for normal cognition, with only the normal and high $\Omega-3: \Omega-6$ diet groups showing normal learning across the 4 days on the Barnes Maze, as shown by a significant decrease in escape latency from day 1 to day 4 . High $\Omega-3: \Omega-6$ supplementation may act through a variety of mechanisms to support normal cognition. Here, it was found that a low $\Omega-3: \Omega-6$ diet was associated with increased oxidative stress within the dentate gyrus, with previous studies demonstrating that oxidative stress contributes to age related impairment in learning and memory (Liu et al., 2003). Furthermore, it was found that a high $\Omega-3: \Omega-6$ diet ratio reduces the hippocampal TNF- $\alpha$ expression. Whilst at basal levels cytokines are intimately involved in cognitive processes (McAfoose and Baune, 2009), their overexpression is associated with increased risk of multiple neuropsychiatric disorders including cognitive decline (McAfoose and Baune, 2009). As cognition-like behavior improved in the high $\Omega-3: \Omega-6$ group while hippocampal TNF$\alpha$ including dentate gyrus TNF- $\alpha$ decreased, this may represent a healthier concentration of TNF- $\alpha$ as compared to the low $\Omega$ 3: $\Omega-6$ group. Interestingly, this decrease in dentate gyrus TNF-a coincided with increased neuronal progenitor proliferation. In this study, $\Omega-3$ supplementation in conjunction with $\Omega-6$ restriction also reduced systemic TNF- $\alpha$ and IFN- $\gamma$ concentration. This is likely to predominantly occur through increased $\Omega-3$ displacing $\Omega-6$ from the common metabolic enzyme pathway leading to increased $\Omega-3$ derived prostaglandins, leukotrienes, and thromboxanes which are less pro-inflammatory than their $\Omega-6$ derived counterparts (Tassoni et al., 2008; Farooqui, 2009; Wall et al., 2010). Additionally, cell culture studies have demonstrated that $\Omega-3$ down regulates the p38 MAPK signaling pathway resulting in decreased nitric oxide synthase, decreasing nitric oxide, TNF- $\alpha$ and prostaglandin E2 (Antonietta Ajmone-Cat et al., 2012). Furthermore, $\Omega-3$ promotes the production of peroxisome 


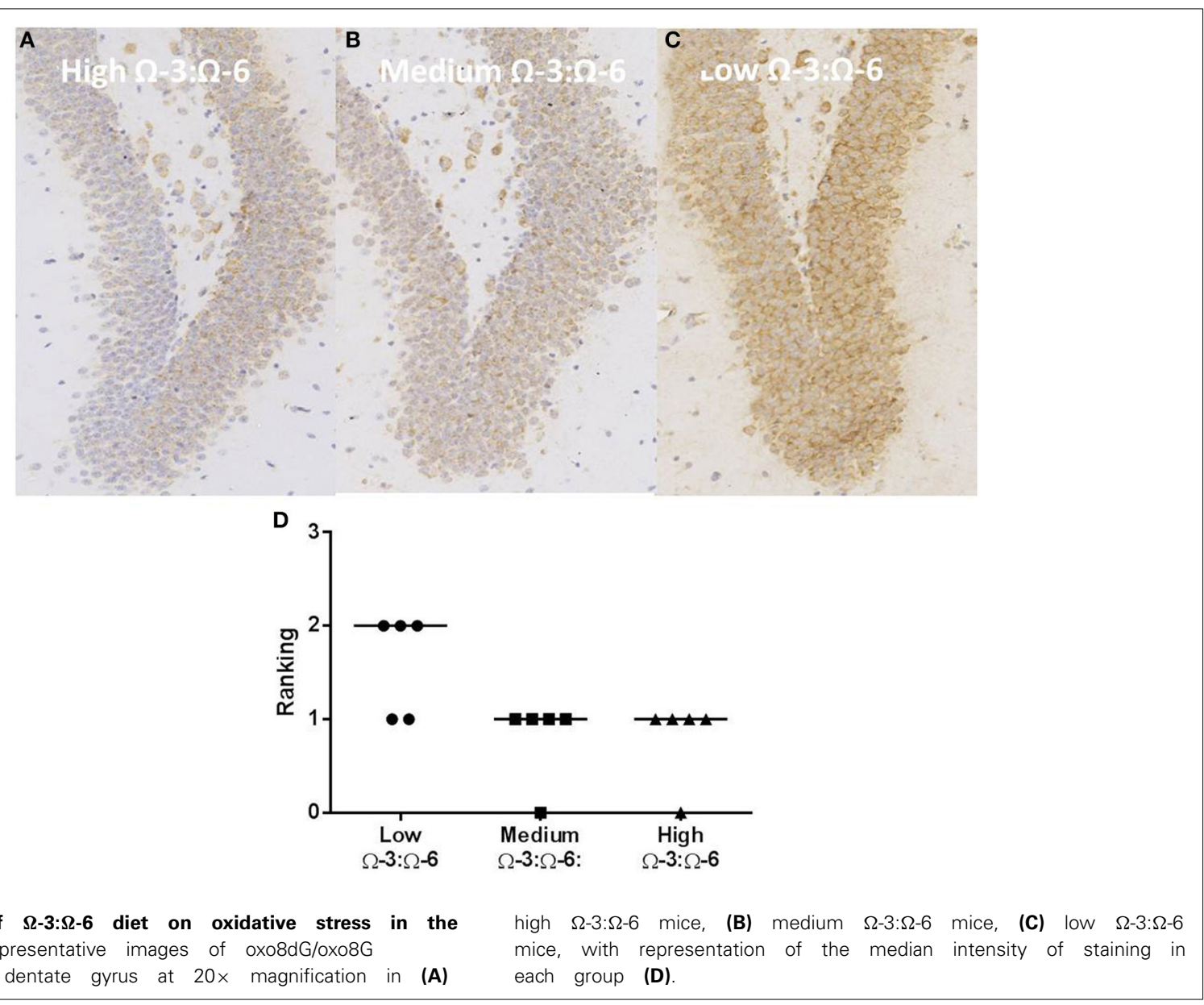

proliferator-activated receptor (PPAR)- $\gamma$, which is known to regulate microglia and astrocyte cytokine production. Lastly, $\Omega-3$ has been demonstrated to reduce pathological microglia and astrocyte activation which occurs with aging (Gupta et al., 2012; Labrousse et al., 2012). The modulation of systemic and central inflammation together appears to promote a neuroprotective environment in these unchallenged mature adult ( 7 month old) WT mice.

Evidence regarding the actions of $\Omega-6$ suggests that while it is an essential fatty acid and necessary in small amounts for good health, large quantities such as in current western diets have been shown to have a detrimental and pro-inflammatory effect (Wall et al., 2010; Blasbalg et al., 2011; Simopoulos, 2011). Thus, the reduction of $\Omega-6$ PUFA in the high $\Omega-3: \Omega-6$ diet may also be contributing to the protective actions of this diet that were observed in our study.

Further potential mechanisms of improved cognition include the promotion of neuronal progenitor proliferation, which was only noted in mice given the high $\Omega-3: \Omega-6$ diet. Increased neurogenesis in the subgranular zone of the hippocampus in young mice (Valente et al., 2009), and in cell culture (Antonietta Ajmone-Cat et al., 2012), have previously been shown to occur with $\Omega-3$ supplementation. This is likely to occur through increased BDNF levels (Jiang et al., 2009), while $\Omega$-3 deprivation has previously been shown to decrease BDNF and phosphorylated
CMP response element binding protein (pCREB) (Bhatia et al., 2011). This is the first study to demonstrate that a high $\Omega-3: \Omega-6$ diet supports adult neurogenesis (as measured by Ki67 and DCX expression in the dentate gyrus). A high $\Omega-3: \Omega-6$ dietary ratio has been demonstrated to have these effects in an approximately middle-age (7 months old) mouse model, supporting a preventative action of $\Omega$-3 PUFA against cognitive decline, thus, investigation of long-term supplementation in young-middle aged human populations may be astute.

In contrast to the demonstrated effects on hippocampal TNF$\alpha$ levels and on neurogenesis, no effect of diet was demonstrated on astrocyte number or microglia number in this hippocampus of this unchallenged mouse model. Current literature suggests that inappropriate microglia activation plays a key degenerative role in the progression of cognitive decline (Antonietta Ajmone-Cat et al., 2012; Czirr and Wyss-Coray, 2012). This study suggests that in an unchallenged mouse model, increased microglia number is not a major contributing factor and other mechanisms such as the promotion of neuronal progenitor proliferation and modulation of cytokine activity may be more significant.

In clinical studies of age related cognitive decline (ARCD) utilizing $\Omega-3$ supplementation, the dose administered varies from $400 \mathrm{mg} /$ day (Geleijnse et al., 2012) to $2800 \mathrm{mg} /$ day (Van De Rest et al., 2008), while doses of up to $9600 \mathrm{mg}$ /day have been trialed in depression. These doses, supplemented to a typical western diet, 
Table 4 | Hippocampus PUFA levels.

\begin{tabular}{|c|c|c|c|}
\hline & $\begin{array}{l}\Omega-3 \text { ( } \% \text { Free } \\
\text { fatty acids) }\end{array}$ & $\begin{array}{l}\Omega-6 \text { ( } \% \text { Free } \\
\text { fatty acids) }\end{array}$ & $\Omega-3: \Omega-6$ \\
\hline Low $\Omega-3: \Omega-6$ & $10.2 \pm 0.61$ & $22.7 \pm 0.78$ & $0.45 \pm 0.01$ \\
\hline Medium $\Omega-3: \Omega-6$ & $12.7 \pm 0.62 *$ & $22.1 \pm 0.71$ & $0.58 \pm 0.03^{*}$ \\
\hline High $\Omega-3: \Omega-6$ & $13.8 \pm 0.54^{* *}$ & $18.0 \pm 0.25^{* * *} \# \#$ & $0.77 \pm 0.04 * * * *$, \\
\hline
\end{tabular}

Representation of $\Omega-3 \Omega-6$ PUFA levels measured in hippocampus. Data analyzed by One-Way ANOVA with Tukey's post-hoc test. ${ }^{*}$ C.F. low $\Omega-3$ diet, ${ }^{\# \# C . F .}$ medium $\Omega-3: \Omega-6$ diet. ${ }^{*} p<0.05,{ }^{* *} p<0.01,{ }^{* * *} p<0.001,{ }^{* * * *} p<0.0001$. Data represents mean $\pm S E M(n=5 /$ group).

result in $\Omega-3: \Omega-6$ PUFA ratios of slightly less than the medium $\Omega-3$ supplementation diet in this study (Blasbalg et al., 2011). The total fat intake of this study was standardized to $5 \%$ making quantification of human equivalent intakes speculative. Fat restriction allows for precise manipulation of the $\Omega-3: \Omega-6$ ratio without using large quantities of $\Omega$-3 PUFA and the increased energy content that comes with fat ingestion. Specifically, in a fat restricted diet, relatively smaller increase in $\Omega-3$ content corresponds to a greater change in $\Omega-3: \Omega-6$ ratio. Thus, achieving a similar $\Omega-3: \Omega-$ 6 ratio as the high $\Omega-3$ mouse diet would require considerable fat restriction, or a targeted reduction of $\Omega-6$ intake (Blasbalg et al., 2011). It will be necessary to monitor whether increasing the dose in future clinical trials proves more efficacious, although consideration must be made to investigating dietary fat restriction coupled with $\Omega-3$ supplementation.

In conclusion, long-term $\Omega-3$ supplementation coupled with $\Omega-6$ restriction was demonstrated to increase anxiety, improve cognitive function, reduce TNF- $\alpha$ expression and enhance neuronal progenitor proliferation in unchallenged mature adult (7 month old) mice. These results support the view that in translational research, the preventive effects of a long-term high $\Omega-3: \Omega-6$ diet in older adults at risk of cognitive decline require further investigation, also addressing the dose required to result in clinically demonstrable preventive effects on cognitive function. It is unclear however whether supplementation such as used in the current study would overcome a long term significantly proinflammatory insult. Further trials investigating $\Omega-3$ supplementation in long term, pro-inflammatory conditions may provide further insight into the efficacy of a high $\Omega-3: \Omega-6$ diet in such conditions. Future studies should also include a wider range of behavioral tests, to confirm the effects of $\Omega-3: \Omega-6$ ratio in diet on anxiety and cognition, at a range of ages up to old age in mice.

\section{AUTHOR CONTRIBUTIONS}

Authors Trent Grundy, Catherine Toben and Bernhard T. Baune designed the study. Author Trent Grundy performed the behavioral experiments, immunohistochemistry and cell analysis, statistical analysis under the supervision of authors Emily J. Jaehne and Frances Corrigan Trent Grundy wrote the first draft of the manuscript. All authors contributed to manuscript revisions and have approved the final manuscript.

\section{ACKNOWLEDGMENTS}

This study was financially supported by the Neuroimmunology Research group of the University of Adelaide. The authors thank
D. Apps from WAS for analyzing the free fatty acids, C. Jawahar for assistance with behavioral and feed protocols and thank $\mathrm{Z}$. Sarnyai for helpful discussions on the topic of this manuscript.

\section{SUPPLEMENTARY MATERIAL}

The Supplementary Material for this article can be found online at: http://www.frontiersin.org/journal/10.3389/fncel.2014. 00399/abstract

\section{REFERENCES}

Antonietta Ajmone-Cat, M., Lavinia Salvatori, M., De Simone, R., Mancini, M., Biagioni, S., Bernardo, A., et al. (2012). Docosahexaenoic acid modulates inflammatory and antineurogenic functions of activated microglial cells. J. Neurosci. Res. 90, 575-587. doi: 10.1002/jnr.22783

Arendash, G. W., Jensen, M. T., Salem, N. Jr., Hussein, N., Cracchiolo, J., Dickson, A., et al. (2007). A diet high in omega-3 fatty acids does not improve or protect cognitive performance in Alzheimer's transgenic mice. Neuroscience 149, 286-302. doi: 10.1016/j.neuroscience.2007.08.018

Arsenault, D., Julien, C., Tremblay, C., and Calon, F. (2011). DHA improves cognition and prevents dysfunction of entorhinal cortex neurons in 3xTg-AD mice. PLoS ONE 6:e17397. doi: 10.1371/journal.pone.0017397

Baune, B. T., Wiede, F., Braun, A., Golledge, J., Arolt, V., and Koerner, H. (2008). Cognitive dysfunction in mice deficient for TNF- and its receptors. Am. J. Med. Genet. B Neuropsychiatr. Genet. 147B, 1056-1064. doi: 10.1002/ajmg.b. 30712

Belzung, C., Leguisquet, A. M., Barreau, S., Delion-Vancassel, S., Chalon, S., and Durand, G. (1998). Alpha-linolenic acid deficiency modifies distractibility but not anxiety and locomotion in rats during aging. J. Nutr. 128, 1537-1542.

Bhatia, H. S., Agrawal, R., Sharma, S., Huo, Y. X., Ying, Z., and Gomez-Pinilla, F. (2011). Omega-3 fatty acid deficiency during brain maturation reduces neuronal and behavioral plasticity in adulthood. PLOS ONE 6:e28451. doi: 10.1371/journal.pone.0028451

Blasbalg, T. L., Hibbeln, J. R., Ramsden, C. E., Majchrzak, S. F., and Rawlings, R. R. (2011). Changes in consumption of omega-3 and omega- 6 fatty acids in the United States during the 20th century. Am. J. Clin. Nutr. 93, 950-962. doi: 10.3945/ajcn.110.006643

Calon, F., Lim, G. P., Morihara, T., Yang, F., Ubeda, O., Salem, N. Jr., et al. (2005). Dietary n-3 polyunsaturated fatty acid depletion activates caspases and decreases NMDA receptors in the brain of a transgenic mouse model of Alzheimer's disease. Eur. J. Neurosci. 22, 617-626. doi: 10.1111/j.14609568.2005.04253.x

Calon, F., Lim, G. P., Yang, F., Morihara, T., Teter, B., Ubeda, O., et al. (2004). Docosahexaenoic acid protects from dendritic pathology in an Alzheimer's disease mouse model. Neuron 43, 633-645. doi: 10.1016/j.neuron.2004.08.013

Camara, M. L., Corrigan, F., Jaehne, E. J., Jawahar, M. C., Anscomb, H., Koerner, H., et al. (2013). TNF-alpha and its receptors modulate complex behaviours and neurotrophins in transgenic mice. Psychoneuroendocrinology 38, 3102-3114. doi: 10.1016/j.psyneuen.2013.09.010

Carrié, I., Clément, M., de Javel, D., Francès, H., and Bourre, J. M. (2000a). Phospholipid supplementation reverses behavioral and biochemical alterations induced by n-3 polyunsaturated fatty acid deficiency in mice. J. Lipid. Res. 41, 473-480.

Carrié, I., Guesnet, P., Bourre, J. M., and Francès, H. (2000b). Diets containing long-chain n-3 polyunsaturated fatty acids affect behaviour differently during development than ageing in mice. Br. J. Nutr. 83, 439-447. doi: 10.1017/S0007 114500000544

Chiu, C. C., Su, K. P., Cheng, T. C., Liu, H. C., Chang, C. J., Dewey, M. E., et al. (2008). The effects of omega-3 fatty acids monotherapy in Alzheimer's disease and mild cognitive impairment: a preliminary randomized doubleblind placebo-controlled study. Prog. Neuropsychopharmacol. Biol. Psychiatry 32, 1538-1544. doi: 10.1016/j.pnpbp.2008.05.015

Czirr, E., and Wyss-Coray, T. (2012). The immunology of neurodegeneration. J. Clin. Invest. 122, 1156-1163. doi: 10.1172/JCI58656

Farooqui, A. A. (2009). Lipid mediators in the neural cell nucleus: their metabolism, signaling, and association with neurological disorders. Neuroscientist 15, 392-407. doi: 10.1177/1073858409337035 
Fedorova, I., and Salem, N. Jr. (2006). Omega-3 fatty acids and rodent behavior. Prostaglandins Leukot. Essent. Fatty Acids 75, 271-289. doi: 10.1016/j.plefa.2006. 07.006

Flint, J. (2003). Animal models of anxiety and their molecular dissection. Semin. Cell Dev. Biol. 14, 37-42. doi: 10.1016/S1084-9521(02)00170-2

Francès, H., Monier, C., and Bourre, J. M. (1995). Effects of dietary alpha-linolenic acid deficiency on neuromuscular and cognitive functions in mice. Life Sci. 57, 1935-1947. doi: 10.1016/0024-3205(95)02180-Q

Francis, H., and Stevenson, R. (2013). The longer-term impacts of Western diet on human cognition and the brain. Appetite 63, 119-128. doi: 10.1016/j.appet.2012.12.018

Freund-Levi, Y., Eriksdotter-Jonhagen, M., Cederholm, T., Basun, H., Faxen-Irving, G., Garlind, A., et al. (2006). Omega-3 fatty acid treatment in 174 patients with mild to moderate Alzheimer disease: OmegAD study: a randomized doubleblind trial. Arch. Neurol. 63, 1402-1408. doi: 10.1001/archneur.63.10.1402

Geleijnse, J. M., Giltay, E. J., and Kromhout, D. (2012). Effects of n-3 fatty acids on cognitive decline: a randomized, double-blind, placebo-controlled trial in stable myocardial infarction patients. Alzheimers Dement. 8, 278-287. doi: 10.1016/j. jalz.2011.06.002

Gibson, R. A., Chen, W., and Makrides, M. (2001). Randomized trials with polyunsaturated fatty acid interventions in preterm and term infants: functional and clinical outcomes. Lipids 36, 873-883. doi: 10.1007/s11745-001-0797-2

Gillette-Guyonnet, S., Secher, M., and Vellas, B. (2013). Nutrition and neurodegeneration: epidemiological evidence and challenges for future research. Br. J. Clin. Pharmacol. 75, 738-755. doi: 10.1111/bcp.12058

Gould, T. D., Dao, D. T., and Kovacsics, C. E. (2009). “The open field test," in Mood and Anxiety Related Phenotypes in Mice, ed T. D. Gould (Baltimore, MD: Humana Press), 1-20. doi: 10.1007/978-1-60761-303-9_1

Gupta, S., Knight, A. G., Keller, J. N., and Bruce-Keller, A. J. (2012). Saturated longchain fatty acids activate inflammatory signaling in astrocytes. J. Neurochem. 120, 1060-1071. doi: 10.1111/j.1471-4159.2012.07660.x

Hart, P. C., Bergner, C. L., Smolinsky, A. N., Dufour, B. D., Egan, R. J., Laporte, J. L., et al. (2010). Experimental models of anxiety for drug discovery and brain research. Methods Mol. Biol. 602, 299-321. doi: 10.1007/978-1-60761058-8_18

Hashimoto, M., Hossain, S., Agdul, H., and Shido, O. (2005). Docosahexaenoic acid-induced amelioration on impairment of memory learning in amyloid betainfused rats relates to the decreases of amyloid beta and cholesterol levels in detergent-insoluble membrane fractions. Biochim. Biophys. Acta 1738, 91-98. doi: 10.1016/j.bbalip.2005.11.011

Hashimoto, M., Hossain, S., Shimada, T., Sugioka, K., Yamasaki, H., Fujii, Y., et al. (2002). Docosahexaenoic acid provides protection from impairment of learning ability in Alzheimer's disease model rats. J. Neurochem. 81, 1084-1091. doi: 10.1046/j.1471-4159.2002.00905.x

Hashimoto, M., Hossain, S., Tanabe, Y., Kawashima, A., Harada, T., Yano, T., et al. (2009). The protective effect of dietary eicosapentaenoic acid against impairment of spatial cognition learning ability in rats infused with amyloid beta(1-40). J. Nutr. Biochem. 20, 965-973. doi: 10.1016/j.jnutbio.2008. 08.009

Hooijmans, C. R., Pasker-De Jong, P. C., De Vries, R. B., and Ritskes-Hoitinga, M. (2012). The effects of long-term omega-3 fatty acid supplementation on cognition and Alzheimer's pathology in animal models of Alzheimer's disease: a systematic review and meta-analysis. J. Alzheimers Dis. 28, 191-209. doi: 10.3233/JAD-2011-111217

Hooijmans, C. R., Rutters, F., Dederen, P. J., Gambarota, G., Veltien, A., Van Groen, T., et al. (2007). Changes in cerebral blood volume and amyloid pathology in aged Alzheimer APP/PS1 mice on a docosahexaenoic acid (DHA) diet or cholesterol enriched Typical Western Diet (TWD). Neurobiol. Dis. 28, 16-29. doi: 10.1016/j.nbd.2007.06.007

Jarrard, L. E. (1993). On the role of the hippocampus in learning and memory in the rat. Behav. Neural Biol. 60, 9-26. doi: 10.1016/0163-1047(93)90664-4

Jiang, L. H., Shi, Y., Wang, L. S., and Yang, Z. R. (2009). The influence of orally administered docosahexaenoic acid on cognitive ability in aged mice. J. Nutr. Biochem. 20, 735-741. doi: 10.1016/j.jnutbio.2008.07.003

Kawakita, E., Hashimoto, M., and Shido, O. (2006). Docosahexaenoic acid promotes neurogenesis in vitro and in vivo. Neuroscience 139, 991-997. doi: 10.1016/j.neuroscience.2006.01.021

Labrousse, V. F., Nadjar, A., Joffre, C., Costes, L., Aubert, A., Gregoire, S., et al. (2012). Short-term long chain omega3 diet protects from neuroinflammatory processes and memory impairment in aged mice. PLoS ONE 7:e36861. doi: 10.1371/journal.pone.0036861

Liu, R., Liu, I. Y., Bi, X., Thompson, R. F., Doctrow, S. R., Malfroy, B., et al. (2003). Reversal of age-related learning deficits and brain oxidative stress in mice with superoxide dismutase/catalase mimetics. Proc. Natl. Acad. Sci. U.S.A. 100, 8526-8531. doi: 10.1073/pnas.1332809100

Loef, M., and Walach, H. (2013). The omega-6/omega-3 ratio and dementia or cognitive decline: a systematic review on human studies and biological evidence. J. Nutr. Gerontol. Geriatr. 32, 1-23. doi: 10.1080/21551197.2012. 752335

Lukiw, W. J., Cui, J. G., Marcheselli, V. L., Bodker, M., Botkjaer, A., Gotlinger, K., et al. (2005). A role for docosahexaenoic acid-derived neuroprotectin D1 in neural cell survival and Alzheimer disease. J. Clin. Invest. 115, 2774-2783. doi: 10.1172/JCI25420

Lumeng, C. N., and Saltiel, A. R. (2011). Inflammatory links between obesity and metabolic disease. J. Clin. Invest. 121, 2111-2117. doi: 10.1172/JCI57132

McAfoose, J., and Baune, B. T. (2009). Evidence for a cytokine model of cognitive function. Neurosci. Biobehav. Rev. 33, 355-366. doi: 10.1016/j.neubiorev.2008.10.005

McAfoose, J., Koerner, H., and Baune, B. T. (2009). The effects of TNF deficiency on age-related cognitive performance. Psychoneuroendocrinology 34, 615-619. doi: 10.1016/j.psyneuen.2008.10.006

McLay, R. N., Freeman, S. M., and Zadina, J. E. (1998). Chronic corticosterone impairs memory performance in the Barnes maze. Physiol. Behav. 63, 933-937. doi: 10.1016/S0031-9384(97)00529-5

McNamara, R. K., Jandacek, R., Rider, T., Tso, P., Cole-Strauss, A., and Lipton, J. W. (2010). Omega-3 fatty acid deficiency increases constitutive proinflammatory cytokine production in rats: relationship with central serotonin turnover. Prostaglandins Leukot. Essent. Fatty Acids 83, 185-191. doi: 10.1016/j.plefa.2010.08.004

Minogue, A. M., Lynch, A. M., Loane, D. J., Herron, C. E., and Lynch, M. A. (2007). Modulation of amyloid-beta-induced and age-associated changes in rat hippocampus by eicosapentaenoic acid. J. Neurochem. 103, 914-926. doi: 10.1111/j.1471-4159.2007.04848.x

Moriguchi, T., Greiner, R. S., and Salem, N. Jr. (2000). Behavioral deficits associated with dietary induction of decreased brain docosahexaenoic acid concentration. J. Neurochem. 75, 2563-2573. doi: 10.1046/j.1471-4159.2000.0752563.x

Nakashima, Y., Yuasa, S., Hukamizu, Y., Okuyama, H., Ohhara, T., Kameyama, T., et al. (1993). Effect of a high linoleate and a high alpha-linolenate diet on general behavior and drug sensitivity in mice. J. Lipid Res. 34, 239-247.

Neves, G., Cooke, S. F., and Bliss, T. V. (2008). Synaptic plasticity, memory and the hippocampus: a neural network approach to causality. Nat. Rev. Neurosci. 9, 65-75. doi: $10.1038 / \mathrm{nrn} 2303$

Oksman, M., Iivonen, H., Hogyes, E., Amtul, Z., Penke, B., Leenders, I., et al. (2006). Impact of different saturated fatty acid, polyunsaturated fatty acid and cholesterol containing diets on beta-amyloid accumulation in APP/PS1 transgenic mice. Neurobiol. Dis. 23, 563-572. doi: 10.1016/j.nbd.2006.04.013

Petursdottir, A. L., Farr, S. A., Morley, J. E., Banks, W. A., and Skuladottir, G. V. (2008). Effect of dietary n-3 polyunsaturated fatty acids on brain lipid fatty acid composition, learning ability, and memory of senescence-accelerated mouse. J. Gerontol. A Biol. Sci. Med. Sci. 63, 1153-1160. doi: 10.1093/gerona/63.11.1153 Raygada, M., Cho, E., and Hilakivi-Clarke, L. (1998). High maternal intake of polyunsaturated fatty acids during pregnancy in mice alters offsprings' aggressive behavior, immobility in the swim test, locomotor activity and brain protein kinase C activity. J. Nutr. 128, 2505-2511.

Reeves, P. G., Nielsen, F. H., and Fahey, G. C. Jr. (1993). AIN-93 purified diets for laboratory rodents: final report of the American Institute of Nutrition ad hoc writing committee on the reformulation of the AIN-76A rodent diet. J. Nutr. 123, 1939-1951.

Rockett, B. D., Harris, M., and Raza Shaikh, S. (2012). High dose of an n-3 polyunsaturated fatty acid diet lowers activity of C57BL/6 mice. Prostaglandins Leukot. Essent. Fatty Acids 86, 137-140. doi: 10.1016/j.plefa.2011.12.001

Rolls, E. T., and Kesner, R. P. (2006). A computational theory of hippocampal function, and empirical tests of the theory. Prog. Neurobiol. 79, 1-48. doi: 10.1016/j.pneurobio.2006.04.005

Rombaldi Bernardi, J., De Souza Escobar, R., Ferreira, C. F., and Pelufo Silveira, P. (2012). Fetal and neonatal levels of omega-3: effects on neurodevelopment, nutrition, and growth. ScientificWorldJournal 2012:202473. doi: $10.1100 / 2012 / 202473$ 
Ryan, A. S., Astwood, J. D., Gautier, S., Kuratko, C. N., Nelson, E. B., and Salem, N. Jr. (2010). Effects of long-chain polyunsaturated fatty acid supplementation on neurodevelopment in childhood: a review of human studies. Prostaglandins Leukot. Essent. Fatty Acids 82, 305-314. doi: 10.1016/j.plefa.2010.02.007

Salem, N. Jr., Litman, B., Kim, H. Y., and Gawrisch, K. (2001). Mechanisms of action of docosahexaenoic acid in the nervous system. Lipids 36, 945-959. doi: 10.1007/s11745-001-0805-6

Simopoulos, A. P. (2011). Evolutionary aspects of diet: the omega-6/omega-3 ratio and the brain. Mol. Neurobiol. 44, 203-215. doi: 10.1007/s12035-010-8162-0

Spencer, J. L., Waters, E. M., Milner, T. A., Lee, F. S., and McEwen, B. S. (2010). BDNF variant Val66Met interacts with estrous cycle in the control of hippocampal function. Proc. Natl. Acad. Sci. U.S.A. 107, 4395-4400. doi: 10.1073/pnas.0915105107

Suchy, J., Chan, A., and Shea, T. B. (2009). Dietary supplementation with a combination of alpha-lipoic acid, acetyl-L-carnitine, glycerophosphocoline, docosahexaenoic acid, and phosphatidylserine reduces oxidative damage to murine brain and improves cognitive performance. Nutrition research 29, 70-74. doi: 10.1016/j.nutres.2008.11.004

Tassoni, D., Kaur, G., Weisinger, R. S., and Sinclair, A. J. (2008). The role of eicosanoids in the brain. Asia Pac. J. Clin. Nutr. 17(Suppl. 1), 220-228.

Tu, W. C., Muhlhausler, B. S., Yelland, L. N., and Gibson, R. A. (2013). Correlations between blood and tissue omega-3 LCPUFA status following dietary ALA intervention in rats. Prostaglandins Leukot. Essent. Fatty Acids 88, 53-60. doi: 10.1016/j.plefa.2012.04.005

Umezawa, M., Ohta, A., Tojo, H., Yagi, H., Hosokawa, M., and Takeda, T. (1995). Dietary alpha-linolenate/linoleate balance influences learning and memory in the senescence-accelerated mouse (SAM). Brain Res. 669, 225-233. doi: 10.1016/0006-8993(94)01250-L

Valente, T., Hidalgo, J., Bolea, I., Ramirez, B., Angles, N., Reguant, J., et al. (2009). A diet enriched in polyphenols and polyunsaturated fatty acids, LMN diet, induces neurogenesis in the subventricular zone and hippocampus of adult mouse brain. J. Alzheimers Dis. 18, 849-865. doi: 10.3233/JAD-2009-1188

Van De Rest, O., Geleijnse, J. M., Kok, F. J., Van Staveren, W. A., Dullemeijer, C., Olderikkert, M. G., et al. (2008). Effect of fish oil on cognitive performance in older subjects: a randomized, controlled trial. Neurology 71, 430-438. doi: 10.1212/01.wnl.0000324268.45138.86

Van Elst, K., Bruining, H., Birtoli, B., Terreaux, C., Buitelaar, J. K., and Kas, M. J. (2014). Food for thought: dietary changes in essential fatty acid ratios and the increase in autism spectrum disorders. Neurosci. Biobehav. Rev. 45c, 369-378. doi: 10.1016/j.neubiorev.2014.07.004

Wainwright, P. E., Xing, H. C., Mutsaers, L., McCutcheon, D., and Kyle, D. (1997). Arachidonic acid offsets the effects on mouse brain and behavior of a diet with a low (n-6):(n-3) ratio and very high levels of docosahexaenoic acid. J. Nutr. 127, 184-193.

Wall, R., Ross, R. P., Fitzgerald, G. F., and Stanton, C. (2010). Fatty acids from fish: the anti-inflammatory potential of long-chain omega-3 fatty acids. Nutr. Rev. 68, 280-289. doi: 10.1111/j.1753-4887.2010.00287.x

Yehuda, S., Rabinovtz, S., Carasso, R. L., and Mostofsky, D. I. (1996). Essential fatty acids preparation (Sr-3) improves Alzheimer's patients quality of life. Int. J. Neurosci. 87, 141-149. doi: 10.3109/00207459609070833

Yurko-Mauro, K., McCarthy, D., Rom, D., Nelson, E. B., Ryan, A. S., Blackwell, A., et al. (2010). Beneficial effects of docosahexaenoic acid on cognition in age-related cognitive decline. Alzheimers Dement. 6, 456-464. doi: 10.1016/j.jalz.2010.01.013

Zhang, W., Hu, X., Yang, W., Gao, Y., and Chen, J. (2010). Omega-3 polyunsaturated fatty acid supplementation confers long-term neuroprotection against neonatal hypoxic-ischemic brain injury through anti-inflammatory actions. Stroke 41, 2341-2347. doi: 10.1161/STROKEAHA.110.586081

Conflict of Interest Statement: The authors declare that the research was conducted in the absence of any commercial or financial relationships that could be construed as a potential conflict of interest.

Received: 11 August 2014; accepted: 05 November 2014; published online: 21 November 2014.

Citation: Grundy T, Toben C, Jaehne EJ, Corrigan F and Baune BT (2014) Long-term omega-3 supplementation modulates behavior, hippocampal fatty acid concentration, neuronal progenitor proliferation and central TNF- $\alpha$ expression in 7 month old unchallenged mice. Front. Cell. Neurosci. 8:399. doi: 10.3389/fncel.2014.00399 This article was submitted to the journal Frontiers in Cellular Neuroscience. Copyright (c) 2014 Grundy, Toben, Jaehne, Corrigan and Baune. This is an openaccess article distributed under the terms of the Creative Commons Attribution License (CC BY). The use, distribution or reproduction in other forums is permitted, provided the original author(s) or licensor are credited and that the original publication in this journal is cited, in accordance with accepted academic practice. No use, distribution or reproduction is permitted which does not comply with these terms. 